\title{
TAKUD JA PAKLAD
}

\author{
VILJA OJA
}

\begin{abstract}
Annotatsioon. Kiutaimede töötlemisel eraldatud lühikeste kiudude ja puitunud osakeste segu nimetatakse kirjakeeles ja põhjaeesti murretes takkudeks, lõunaeesti murretes pakaldeks. Ropsitakke märgivad põhjaeesti murretes ropsi- või ropstakud, roogetakud, eisted ja eietakud, lõunaeesti murretes raba- ja lemmtüvest moodustatud sõnad ning rehike või rehikpakla. Hõreda harjaga sugedes saadakse otstakud, mille murdenimetused lähtuvad sõnast ots. Tiheda harja alt tulevaid takke on põhjaeestlased nimetanud sõnadega peentakud vms, ihuroogeja ihutakud ning lagijad ehk lagijatakud, lõunaeestlased laas- ehk laasikpakla, laasiku vms, suikatsõ (pakla) ning ladviku ehk ladvaotsigu.
\end{abstract}

Võtmesõnad: takk, pakal, ropsitakud, sugetakud, takunimetuste levikukaardid, eesti murded

\section{Sissejuhatus}

Lina või kanepi töötlemisel eraldatud lühikeste kiudude ja puitunud osakeste segu on takk, murdekeeles ka pakal. Mõlemaid sõnu kasutatakse enamasti mitmuse vormis. Takke on mitut sorti ja üldnimetustele lisaks on olemas muud, kitsama tähendusega nimetused. Kui kirjakeelsed nimetused leiame hõlpsasti sõnaraamatutest, siis murdesõnad, nagu lagijad, roopjad, laasiku, raviku, reh(i)ke, jäävad paljudele arusaamatuks. Järgnev ülevaade, kus käsitletakse takunimetuste tähendusi ja levikut, peaks asjasse selgust tooma. Lisatud on viited sõnade päritolule ning sarnastele nimetustele teistes läänemeresoome keeltes. Algmaterjal pärineb Eesti murrete ja soome-ugri keelte arhiivist (EMSUKA), soomekeelne võrdlusaines Soome murrete sõnaarhiivist (SMSA), kuid arvesse on võetud ka läänemeresoome keeleatlase jaoks kogutud ainest. (Materjali keerukuse ja keeliti ilmnevate suurte erinevuste tõttu jäeti see atlases kaardistamata.) Näidetes on kasutatud lihtsustatud murdetranskriptsiooni. Enne

${ }^{1}$ Uurimistööd on rahastanud SF0050037s10 ja ETF9367. 
nimetustesse süvenemist selgitan lühidalt takkude saamist, kirjeldades vanaaegset kiutaimede töötlemise protsessi.

\section{Kuidas takke saadi}

Kanepist tegid eestlased peamiselt köisi ja võrgunööri. Kangakudumiseks kasutati lina, mistõttu seda kasvatati tunduvalt rohkem kui kanepit. Takkude eraldamise menetlus on mõlema kiutaime puhul põhimõtteliselt sama, kuid lina töödeldi peenema kiu saamiseks põhjalikumalt ja nii tekkis eri sorti linatakke samuti rohkem. Seepärast on järgneva käsitluse aluseks linatöötlemine. Kõige usinamalt tegeldi linakasvatusega Lõuna-Eestis ja Läänemaal Vigala ümbruses, kus linamüügiga teeniti suur osa talu sissetulekust (ERL: 139; Manninen 1933: 130-142). Nendest piirkondadest on ka sellealast sõnavara kirja pandud enam kui mujalt.

Põlva keelejuht on linatöötlemise protsessi väljendanud ühe lausega: linnu kakutass, ’suitass, 'leotadass, ’laotadass, kuivatadass, kö̈̈detäss punda, rabatass, kammitass (EMSUKA). Igaks juhuks seletan selle kirjakeeles veidi pikemalt lahti. Lina kitkuti põllul käsitsi, seoti peodesse ning laoti hakkidesse. Hakkidest veeti linapeod kokku ja eemaldati kraasiga ehk raatsiga kuprad. Seda tegevust on Võrumaal kohati nimetatud ka sugemiseks, nt 'Suiti kuku? otsast maha? Kan (KVVE: 13). Varred pandi üheks kuni kolmeks nädalaks likku, misjärel laotati väljale tahenema ja viidi sealt hiljem rehetuppa partele kuivama. Kuivanud linadel kolgiti ehk lõugutati luud (puitunud osad) kiudude küljest lahti. Purustatud linaluud eraldati kiududest ropsimõõgaga ropsides ja saadi esimesed, jämedad takud. Järgnes linade harjamine (ehk sugemine) ja kammimine, mille käigus eraldus järjest peenemaid takke (vt nt Ränk 1995: 102-103; ERL: 139-141). Laias laastus eristatakse kaht sorti takke: ropsi- ja sugetakud. Tegelikult tekib sugetakke olenevalt linaharja tihedusest omakorda mitut sorti. Siinses käsitluses on nimetused jagatud sisu järgi esmalt kolmeks: üldnimetused, ropsitakud, sugetakud, ning viimane rühm omakorda kolmeks: otstakud, keskmised takud ja peentakud. 


\section{2. Üldnimetused}

Sõnad takk ja pakal märgivad igasugust takku, ent kummalgi neist on murretes oma kindel levila. Põhjaeesti murretes on üldlevinud takk (pl takud, takod, tagud, R takkud), lõunaeesti murretes pakal (pakaĺ, pakõl, pakl, pl 'pakla, 'pakla’, 'pakle, 'paklõ'). Põhja- ja lõunaeesti murrete piirialal esinevad takk ja pakal paralleelselt (vt kaart 1). Harilikult tarvitatakse neid sõnu mitmuse vormis. Põhjuseks on ilmselt see, et takud moodustuvad paljudest linakiutükkidest. Ainsuse kuju kohtame sageli liitsõnade esiosana, nt takukoonal, takunöör. Lähisugukeeltes on kumbagi nimetust kasutatud vähesel määral: takku isuri, vadja ja mõnes soome murdes (Kullaa, Ulvila, Pori, Suoniemi, Pyhäntä, Kallivere) ning pakli läänevadja murdes. Sõna takku märgib laiemalt põhjapoolsetes läänemeresoome keeltes sagris karva ja villa, sassis juukseid, heina vms ning seda ongi peetud noomeni algupärasemaks tähenduseks (EEW: 3054-3055; Saareste 1924: 23). Sõnatüve seostatakse verbidega takerduma, takistama jms (SKES: 1209; SSA 3: 259). Eesti pakal on läti laen (<1t pakula, pakuls, pl pakulas; Vaba 1997: 148). Vadja läänemurdesse on pakli tulnud vene keelest (< vn пакля), kus see on samuti balti päritoluga (< leedu pãkulos; Vasmer 3: 189).

Kaart 1. Taku üldnimetused eesti murretes

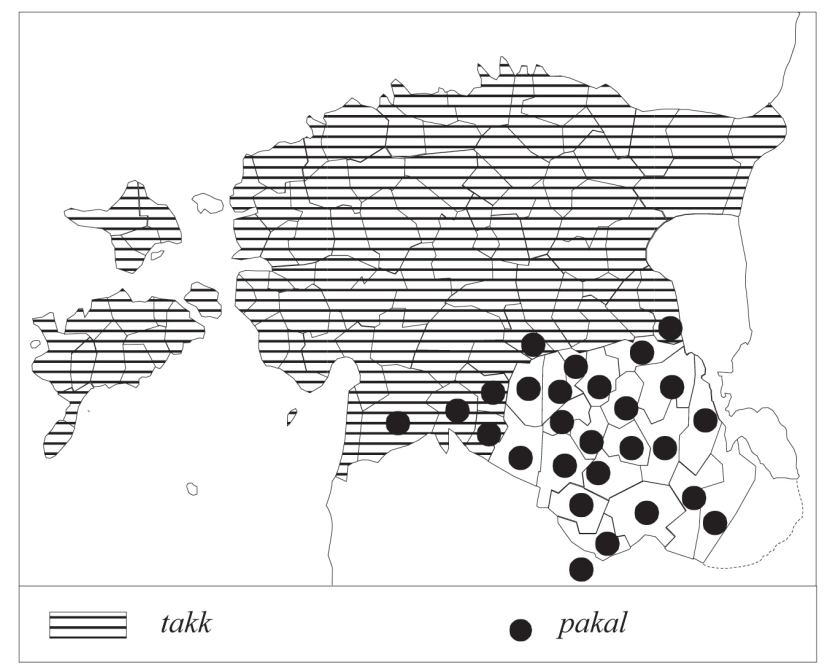


Takust kedratud lõnga, sellest kootud kangast ja niisugusest kangast tehtud tooteid iseloomustavad ne- ja kas-liitelised adjektiivid takune eP (S L ka takne), takukas Kse JMd Trm Kod ja ’paklane eL (V -õ), ’pakline Saa Hls Krk San Har Plv. Näiteks Siss `anti neile kaits ’paklast amet ja kaits ’paari paklasi ’ükse Pst (Tanning 1961: 180). Kui sooviti täpsustada, kas jutt käib lina- või kanepitakust, lisati asjakohane täiendsõna, nt lina pakla? Krl; Leimed ma kedrasi kanepitaksed Kaa. Üldnimetused on ka eri takusorte tähistavate liitnimetuste põhisõnaks (vt osad 3 ja 4).

\section{Ropsitakud}

Kõige jämedamad takud tekkisid, nagu öeldud, puitunud osakeste eraldamisel lõugutatud linadest. Seda tööd tehti varem käsitsi suure noa taolise puust tööriistaga, ropsimõõgaga pekstes või rapsides, hiljem linavurri abil. Kui taheti saada kvaliteetsemat lina, eelistati siiski käsitsitööd, sest linavurriga kippus kiud sassi minema. Ropsimõõka ja sellega töötamist väljendavad murdeti eri sõnad ning selle tõttu on ka saadud takke isemoodi nimetatud. Mõnikord on öeldud lihtsalt jämedad takud eP, jämetakk Tõs, ¡ämme ’pakla Trv, suureluu takk Vig, ent need pole nimetused, vaid pigem seletused. Liitnimetused täiendsõnaga jäme- väljendavad peale ropsitakkude ka hõreda harjaga töödeldud sugetakke (vt osa 4). Ropsitakke kasutati ehitusel tihendus- ja soojustusmaterjalina ning neist keerutati nööri ja kooti kotiriiet (Ränk 1995: 207; ERL: 287). Otstarbe järgi ongi ropsitakke vahel nimetatud sõnaga eietakud Juu Koe (< eie 'takune nöör'; vt EMS I: 618) või kotitakud Mär. Viimast liitsõna on ühtlasi kasutatud jämedate sugetakkude kohta (vt osa 4.2).

Kirjakeeles tuntud nimetus ropsitakud on Wiedemanni sõnaraamatus (1973: 974) esitatud märksõna rops artiklis koos viitega eesti murdevastele roogetakud. Põhjaeesti murretes on nii genitiivse kui ka nominatiivse täiendosaga liitsõnu: ropsitakud S ( ropse- Pöi Muh) Kse Hää Saa, kohati K (KJn ka ropsi paklad) IPõ; ropstakud R (-takkud, -tagud) Kei JJn Kad VJg I (vt kaart 2). Verb ropsima arvatakse tulenevat onomatopöast (<rops) ja sama tüvega tuletisi leidub kõigis läänemeresoome keeltes, kuid mitte linatöötlusprotsessi väljendavate sõnadena (EEW: 2543-2544; SKES: 840; SSA 3: 93).

Läänemurdeline sõna linaropsimise kohta on rookima. Selleks tööks kasutatavat riista märgib nimetus rooge- või rookemõõ k ja saadud takke 
roogetakud Muh Lä PäPõ või 'rooketakud Tõs. Verb rookima esineb eesti keeles põhiliselt kahes tähenduses: 'puhastama (millestki)' ja 'peksma, kloppima' (EKSS 4: 876). Murdekeelsed tähendused 'linu ropsima' ja 'nahka parkima' seostuvad sisuliselt viimasega (EMSUKA; Wiedemann 1973: 976-977). Läänemeresoome rookima/ruokkia arvatakse olevat germaani päritolu, vrd muinaspõhja *rōkian, kasks rōken (EEW: 2532-2533; SKES: 871-872; SSA 3: 106). Tähenduses 'linu ropsima' pole seda sõna olemasolevate teadete kohaselt lähisugukeeltes kasutatud.

Põhjaeestikeelse ropsima ja rookima vaste lõunaeesti murdeis on rabama ning tööriist on rapai. Samast tüvest on tulnud takunimetused rabaaludse ('pakla, -a') Rõn Har Lut, rabakalo|sõ, -ssõ, -dsõ ('pakla') Urv Rõu Vas Se, rabak pakla Plv, rabik pakla (-e) San Krl, rabik|u, -a, -e, -õ Kam San ( rabake) Kan Urv Har, rapikõ San Räp, ravi|ku, -gu, -ke Krk Hel T (kaardil 2 on näidatud raba-tüvest tulnud nimetuste üldlevik). Näiteks Rabamise man ‘saiva rabakalodsõ ${ }^{p}$ 'pakla? Se (KVVE: 301); ravike olli nuu 'pakla, mes 'linnu rabaden rabajaga maha 'peśti Nõo; Rabaten 'saadi rabike ( rabake rabiku), noist tetä midagi es saa San (EMSUKA). Verbi rabada/ravata tuntakse eesti keeles ja lähisugukeeltes tähenduses 'lüüa, peksta (viljavihke terade eraldamiseks)'. Päritolult peetakse seda deskriptiivsõnaks ja seostatakse kahtlemisi verbiga raputama, kuid selle kohta on esitatud ka laenuetümoloogia: < germ *draban, vrd gooti (ga-)draban 'lüüa, peksta' (EEW: 2372-2373; Koivulehto 1974: 121-122; SSA 3: 57).

Selle kõrval on Lõuna-Eestis kasutatud kitsama levikuga nimetusi. Tartu ja Võru murdeala idatiival esineb rehik pl rehike ('rehke?, 'rehke?') Võn Kam Krl Räp Se; rehik pakl|ad (-a') Võn Plv, nt 'rehke? omma

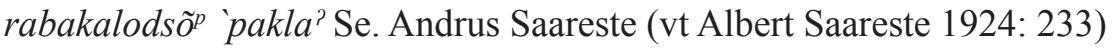
on avaldanud kahtlust sõna tähenduse suhtes. Wiedemanni sõnaraamatus (1973: 947) leidub peale substantiivi ka adjektiiv rehkine 'paha, vilets (taku kohta)'. Noomeni aluseks olev verb rehkmä on tuntud lõunaeesti murretes tähenduses 'peksma, materdama jms'. Päritolult peetakse seda läänemeresoome deskriptiivtüveks ja ühendatakse soome verbiga rehkiä, vepsa rehkta, karjala riehkie jms (EEW: 2445; SKES: 756; SSA 3: 59).

Võru murde lääneosa ja Sangaste keelejuhtide sõnul saadi ropsimise tulemusel lemmike vms, pl lemmi|ke (-ke?, -ge?, -kä, -kä’) San Urv Krl $\left(\sim-k \tilde{o}^{3}\right.$, lemminge) Har Rõu. Samast tüvest võiks olla tulnud mulgi- ja tartumurdeline lemmel pl `lemle (d) M (Pst `lem(b)le paklad) Puh Kam 
Kaart 2. Ropsitakkude nimetused eesti murretes

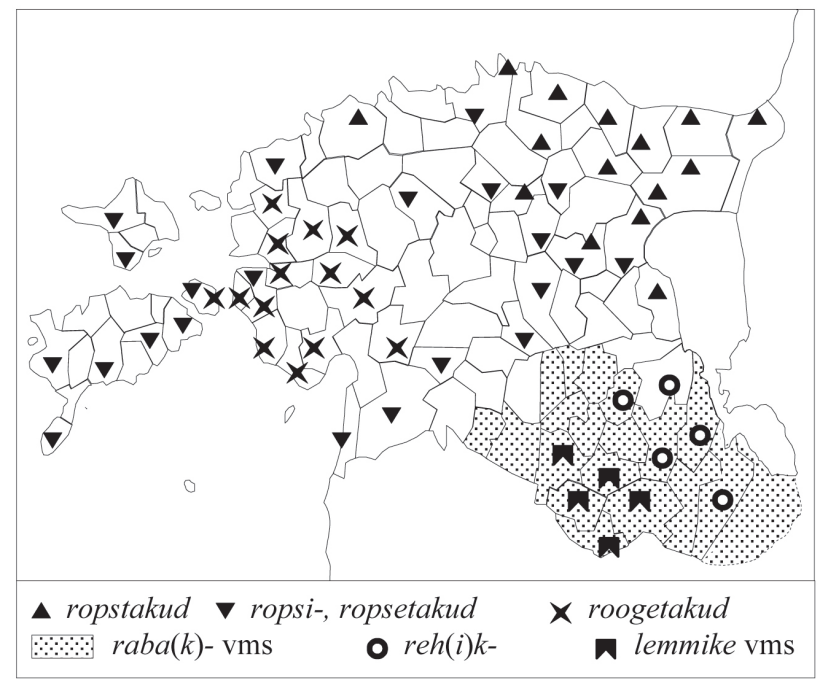

Ote ning lemme pl 'lemmed Koe ja Vil. Nende sõnade tähendus varieerub (vt ka EMS V: 91, 93). Osa näiteid räägib selgelt ropsitakkudest, nt lemmikä `olli nu kõgõ `õelaba ’paklõ Urv; rabaja aludsõ ’pakla om lemminge $\mathrm{Krl}$, teine osa linaluudest, linapurust või -ebemetest, nt lina `lemmed on kõikse peenem udu takk Koe (EMSUKA). Mõnest kirjapanekust tähendus ei selgu, nt San rabavuse lemmike. Wiedemanni (1973: 486) järgi on lina lemmed ja Mulgi leml, lina lemlid 'linaluud', aga sõna lemmik pl lemmike tähenduseks on antud 'ropsitakud'.

Keskmurdes on mitmes tähenduses kasutatud sõna 'eisted (pl) Jür Koe Ksi Plt: 1. kiupuru, ebe, helves; 2a. linaseemneaganad, 2b. ropsitakud, nt 'eisted on nied, mis takkudest 'välla puistatakse Jür; 'eisted on vad ropsi takud, mis lina 'ropsimisega maha jäävad Koe (EMS I: 636). Wiedemann (1973: 89) annab eiste pl eisted = ebe, ebemed. Üksikud teated on järgmiste ropsitaku nimetuste kohta: roopjad (> roopjased 'takused'), roopjatakud Kod ja luised $(<$ luu $) \sim$ ropstagud Vai. 


\section{Sugetakud}

Ropsitud linu töödeldi linaharjaga ${ }^{2}$ ehk soeti kaks või kolm korda, esmalt hõreda, pärast tiheda harjaga ning sellest olenevalt saadi ka kaht või kolme sorti takke. Sugemisel tekkivaid takke on kirjakeeles nimetatud sugetakkudeks (EKSS 5: 341; ÕS 2006: 869). Kõigis läänemeresoome keeltes väljendab noomen suga/suka (hobuse) kammi vms ja suge-tüveline verb mõistet 'harjama, kammima', ent tähenduse 'linaharjaga töötlema' kohta lähisugukeeltest teateid pole. Sama tüvega sõnu leidub ka teistes Uurali keeltes ja selle tüve juured ulatuvad indoiraani keeltesse, vrd nt sanskriti sùka 'aganad, ogad, seaharjased vms', avaari sūkā- 'oga, okas, astel', vanaindia śūka- 'sõkal, agan' (SSA 3: 209). Samamoodi nagu eesti keeles suga kasutatakse läti keeles sõna suka tähenduses '(hobuse)suga' ja leedu keeles sõna šùkos 'linahari'. Julius Mägiste ei pea tõenäoliseks, et läänemeresoome suga oleks balti keeltest laenatud, kuid arvab, et leedu-läti noomen võib olla läänemeresoome keeltest semasioloogiliselt mõjutatud (EEW: 2892-2893).

Eesti murretes tarvitatakse sugema-verbist moodustatud takunimetusi suhteliselt vähe: sugitakud KuuK Trm; soetakud Vig Aud PJg Juu; sugemise (-mese) takud Emm Lai; 'suikatsõ ( pakla) Kan Urv Vas Räp Se Lut. Tähenduse poolest ei ole need identsed. Põhjaeesti murretes on sel viisil tähistatud üldmõistet - linadest sugemisel saadavaid takke (nt soetakud, mis soetakse, otsmised ja peened takud Juu), Võru murde 'suikatsõ on aga peentaku nimetus (vt osa 4.3). Tavaliselt väljendavad soetud takke murdekeeles üldnimetuse asemel konkreetseid takusorte märkivad nimetused (vt osad 4.1-4.3). Võrdluseks olgu lisatud, et soomekeelsed sugetakkude nimetused lähtuvad harja-tüvest: harjeet, harja|rohtimet, harja(n)|tappurat.

Erisuguse kvaliteediga sugetakkudest kedrati jämedamat ja peenemat lõnga, millest kooti kangast meeste tööpükste, naiste särgialaste ja muude jämedakoeliste esemete valmistamiseks (Ränk 1995: 207; ERL: 287). Näiteks Tarvastu keelejuht jutustas: 'Mitmat 'muudu 'õnga kedräti,jämet ja peenikest. Edimese otsast `suituse, nii olive jämme, nii kedräti koti

2 Linahari oli u 70-80 cm pikkune laud, mille kummaski otsas asetses neljakandiline 3-5 cm pikkuste metallpiidega pesa, üks hõredam, teine tihedam. Oli ka ühe pesaga linaharju. Neist linapeosid läbi tõmmates eraldati kiududest takud (ERL: 139; Ränk 1995: 102). 
lõngasse. Nii olive `ämme ’pakla justku vana ’jorkama. Mis peenema pakla, neist kedräti peenemat 'lõnga, 'koeti jälle peenemase kottesse (Tanning 1961: 191).

\subsection{Otstakud}

Hõreda harjaga sugemisel saadud takkude kirjakeelne nimetus on otstakud (EKSS 3: 858; ÕS 1999: 539). Murretes on ots-sõnast moodustatud nimetused hästi tuntud. Esineb nii nimetavalise kui ka omastavalise täiendosaga liitnimetusi, mille põhisõnaks on taku üldnimetus (tavaliselt mitmuse vormis): pl ots|takud (-takod) Mar Hää Saa Jür Amb Koe VMr VJg Plt KJn, -tagud või -takkud R; ôts|takud I, -takkud Lüg; ots| 'pakla(d) (-e, - $\left.a^{\prime}\right)$ Saa Vil Trv Hls Krk Ote Har Räp; otsa|takud Jäm Khk Pöi Muh Emm Mär Vig Kse Var Tõs Aud (otse-) PJg Hää Juu Äks, õtsa- Iis; otsa| 'pakla Nõo.

Peale selle on murdekeeles (eriti Lõuna-Eestis) levinud ots-tüvelised tuletised: otsik > otsikud (pl) KJn, otsi|ku ('pakla) Trv Krk (-gu) Hel Puh (-kud), -ke(t) Ran, -kõ San; otsik pakla $\left(-a^{2},-e,-\tilde{o}^{\prime}\right)$ Krk Nõo San $(\sim$ otsk) Krl Plv, nt `Pakla puistati vardaga ärä ja mähiti kuutslide, iks otsikpakla erälde (Keem 1995: 97); otsikane > otsikatsõ 'pakla? Urv Plv Vas Se; 'otskatse (-dsõ) 'pakla (-a') Kam Urv Vas Se, nt Edimält tõmmate läbi hõrrõ hara, siss 'saiva 'otskatsõ ${ }^{p}$ 'pakla’ Se (KVVE: 301); otsmine > 'otsmised takud Lai; 'otsmene takk Juu; otsmane > 'otsmased (takud) KuuK, 'otsmatsõ 'pakla? Kan, nt 'otsmatsõ 'pakla' omma nuи', mis edimätsest harast omma läbi 'suitu, 'otsmatsõ 'pakla? omma hõelamba? Kan (EMSUKA). Sõnast otsik moodustatud ne-tuletisi otsikine Krk San, otsiklene Hää, otsikne pl otsiksed Hää Saa on kasutatud nii substantiivina tähenduses 'otstakk' kui ka adjektiivina 'otstakune'.

Nimetused otstakud, otsiku 'pakla jms tähistavad harilikult esimesel sugemisel saadud jämedaid sugetakke ning järgmis(t)el sugemis(t)el eraldunud takud kannavad muud nime, nt Trv otsiku 'pakla ja laasiku 'pakla (vt osad 4.2, 4.3). Üks Karksi murraku keelejuht seevastu on otsikute hulgas eristanud jämedamaid ja peenemaid takke, nt nii otsa raksi, nii om otsiku; tüve otsigu (tüviku -gu) saave koti lõimess, ladva otsigu (ladviku -gu) saave koti koess Krk. Selle järgi võiks otsiku siin märkida sama üldmõistet, mis kirjakeeles sugetakud (vt osa 4). Eesti murretest nimetuse tüviku/tüvigu kohta rohkem teateid pole, ladviku tähistab aga peentakku (vt osa 4.3). Soome murretes esinevad samade nimetamis- 
motiividega sõnad, ent vastupidises tähenduses: latviaiset, latvarohtimet, latvatappurat vms on 'harjamisel saadud kõige jämedamad takud' ning tüve- või tüvitappurat 'peenemad takud', nt Alahärmä latvatappurat karkeita 'jämedad', tüvitappurat hienompia 'ilusamad, peenemad' (SMSA). Hõreda harjaga sugedes tekkinud takkude kohta on eestlased öelnud ka lihtsalt jämedaharjatakud Kul,jämedarja takod Mar, jämearjatakud Muh või jämedamad takud $\mathrm{VNg}$, mille sisu on enamasti arusaadav, ent need pole nimetused, vaid seletused.

\subsection{Keskmised takud}

Kui sooviti saada hästi hea kvaliteediga lina, soeti kiude kolm korda. Sel juhul ei nimetatud teisel sugemisel saadud takke peentakkudeks nagu kahekordse sugemise puhul, vaid lähtuti mõistest 'keskmine, vahepealne'. Näiteks sugemese takud, kolm 'sorti - otsa takud, kesmesed takud, peeniksed takud PJg; Ot́siksed, kesstakud ja peeniksed takud Hää; õtstakku ‘suetasse sõreda arjaga, kesktakku ‘tihkemä puale piäl Kod; Jämajast on kirja pandud vahelised takud. Kirderannikumurde idaosas ja idamurdes väljendab keskmisi takke liitsõna täiendosaga lõim- (Vai loim-). Nagu nimetus osutab, valmistati sellest lõimelõnga (nt kesktakuss kedräsimä ükspidike 'õime ja käe käteräte 'lõime Kod), kuid keskmisest takust kedrati ka jämeda kanga koelõnga (nt kesstakud `soetaks ’kesmese arja pääl, vanasti koeti neist püksikangast ja nõude käterätikusi Hää).

Keskmiste takkude eesti- ja soomekeelsed nimetused on üsna sarnased, vrd sm keskiäiset, keski-, keskiäis- või kesku|rohtimet jms; väliäiset, väli|tappurat, -harjeet, -rohtimet; loimet ja loimi|rohtimet (SMS 6: 877, 880; SMSA). Eesti Nõo-murdeline koti ’pakla ja Järva-Jaani jämedad takud on kirjeldavat laadi ühendid. Täiendsõnu koti- ja jämedad kohtame nii ropsitakkude kui ka otstakkude nimetustes (vt osad 3 ja 4.1). Näiteks Järva-Jaani lauses takud sai kolmes `järkus 'suetud: kotitakud, jämedad takud ja ’piened takud tähistab sõna kotitakud hoopis esimesi sugetakke ehk otstakke.

\subsection{Peentakud}

Olenemata sellest, kas sugemisi oli kaks või kolm, nimetati viimaseid takke paljudes põhjaeesti murrakutes peenteks või peene harja takkudeks: 
'peened ('piened) takud R (tagud v takkud) Jäm Kse Juu KuuK JJn Koe; peeniksed takud Krj Pöi Mar Tõs PJg Hää Lai Plt; peenikse ’pakle Krk; peen- (pien)takk, -takud Var Tõs Jür Amb Iis Trm, -takkud Lüg; peene arja takud Pöi Muh Kul Mär Vig; peeniks(e)arja (peenikarja) takod Mar (kaart 3). Soome murretes esineb sama täiendsõnaga nimetus pienet rohtimet ja viimase tähendusvaste pikku|rohtimet (soome pieni = pikku'väike').

Lõunaeesti murdes ning selle naabruses märgivad peentakke laastüvest moodustatud nimetused (hrl mitm): laaśtakud Äks Lai KJn; laaspakal Saa Vil Hls Krk Ote Har; laasik(pakal) M TLä Krl Har Lei (-ž-), laaśk- Võn Kam Rõn San Har Plv Räp (nt peräst tulliva laasik pakla ehk laasiku Nõo). Sageli on tarvitatud ne-tuletisi, peamiselt omadussõna funktsioonis: laasikene või 'laaśkene (pakal) Saa Nõo Võn Kam Rõn (nt sugida tuleb 'otskene (pakal) enne ja laaśkene (pakal) perän Kam); laasikine (lõng) Krk; laasikanõ või laaśkanõ (pakal) V (nt 'laaśkatsõ 'pakla? omma? ilosa?, tõsõst haŕast 'suitu? Kan), Lei pl laažiklõdzõ (vt EMS IV: 769-771, 773). Noomenit seostatakse verbiga laasima 'puutüvelt oksi eemaldama'; murdes ka 'oksi või lehti variseda laskma' (EEW: 1193). Sõnatüve päritolu ei ole selge.

Kaart 3. Peentakkude nimetusi

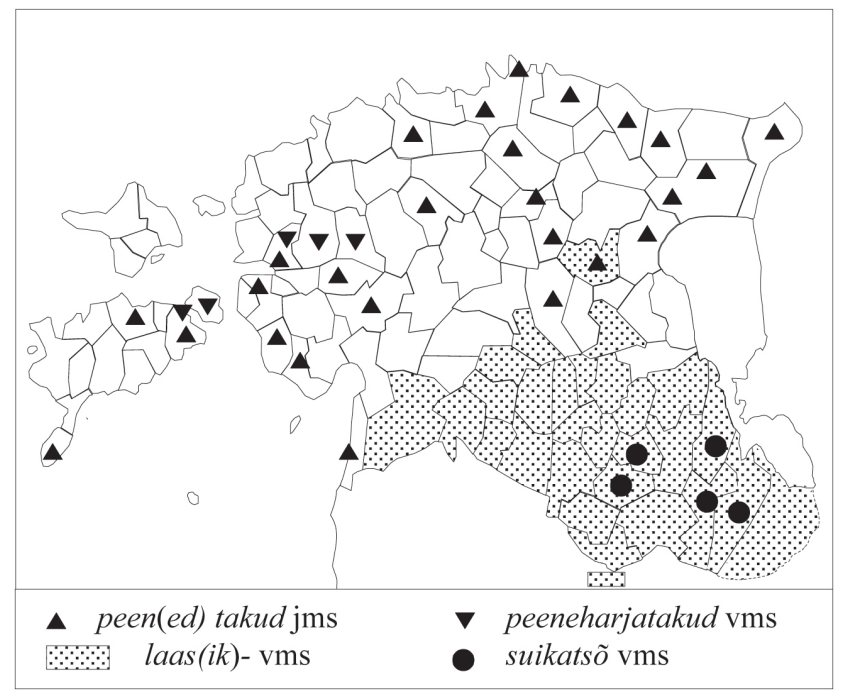


Võru murdes (Kan Urv Vas Räp Se Lut) käibib paralleelnimetus `suikatsõ ('pakla), nt 'suikatsõ 'pakla? omma laasikadsõ 'pakla?, nuu paŕemba 'pakla? Urv. Karksi murrakus on peentaku kohta öeldud ladva otsigu ja ladviku (-gu) pl < latv (vt ka osa 4.1), nt ladvikise 'peentest takkudest' lõnga, ladvikitest tett Krk (EMS IV: 796-797). Analoogiline nimetus märgib teisel sugemisel eraldunud takku keskvepsa murdes Järvenküläs: ladvez (g ladvesen) < ladv 'latv'.

Põhja-Eestist on üksikteated sõnade ihutakud (nt ihu takud, nee on paramad, otsatakud on 'vaesemad Khk) ja ihuroogetakud kohta (nt ihuroogetakud oo ilusad 'peened, need 'tehti 'eńni koti 'kanga kueks Mär(EMS I: 888). Soome murretes märgib iho muu hulgas linakiude ja kõige peenemaid takke. Takunimetustena kasutatakse ka tuletisi, nagu ihokaiset, ihonaiset, ihorohtimet, ihokaisrohdimet (SMS 4: 728-732). Üksnes Kodavere murrakust on kirja pandud noomenid lagijad, lagijatakud, lagijalinatakk 'peentakk' (nt lagijad one piänike takk, kõege piänem takk) ning lagijane 'peentakune' (nt lagijased longad) (EMS IV: 808). Parima kvaliteediga takkudest kedrati sageli koelõnga lihtsama kanga jaoks, millest valmistati näiteks särgialaseid, käterätte, linu ja väiksemaid kotte.

\section{Kokkuvõtteks}

Takkude üldnimetus on põhjaeesti murretes takk, lõunaeesti murretes pakal. Enamasti kasutatakse kõiki nimetusi mitmuse vormis. Kõige jämedamaid, ropsimisel eralduvaid takke nimetatakse põhjaeesti murretes ropsivõi ropstakkudeks (< rops), läänemurdes roogetakkudeks (< rookima). Lõunaeesti murretes on valdavaks verbist rabama 'ropsima' lähtunud nimetused, nagu rabaalutse, rabakpakla, rapikõ, raviku. Samas tähenduses kasutatakse Kagu-Eestis sõnu rehike ja rehikpakla ning lemmike vms.

Kirjakeelse üldnimetuse sugetakud asemel eelistatakse murretes konkreetset takusorti märkivaid sõnu. Sugetakke eristati sugemiskordade alusel kaht või kolme sorti. Esimesel sugemisel hõreda harjaga eraldusid otstakud. Murdekeelsetes liitnimetustes on esikomponent ots kas nominatiivi või genitiivi vormis. Peale nende leidub nimetuste hulgas rida tuletisi nimisõnast ots, nagu otsiku, otsikatse, 'otsmased. Kolme sugemise korral olid teised takud kesk-ehk keskmised või vahetakud. Viimasel sugemisel saadi peentakud. Peentakke tähistatakse põhjaeesti murretes tavaliselt liitnimetusega, mille täiendsõnaks on adjektiiv peen või peenike, nagu 
peened takud, peeneharjatakud. Lõunaeesti murretes on laialt levinud laas-tüvelised nimetused laas(ik)pakla, laasiku vms. Selle kõrval on Võru murdes peentakke nimetatud ‘suikatsõ ('pakla). Mõne takunimetuse kohta on üksikteateid, mille alusel üldistusi teha ei söanda.

Lähisugukeelte sõnadega ühiseid nimetusi on eesti murretes vähe. Isuri ja vadja keeles ning mõnes soome murdes esineb üldnimetus takut ning läänevadja murdes pakli. Soome murretes leidub sama täiendsõnaga peentaku nimetusi nagu eesti murretes: pienet rohtimet ja ihorohtimet. Keskmisel sugemiskorral saadud takke märkivatel eesti ja soome sõnadel on ühesugused nimetamismotiivid: 'keskmine', 'vahe(pealne)' ning 'lõim'. Eesti Karksi murrakus on jämedaid sugetakke nimetatud tüviku/ tüvigu ning peentakke ladviku, aga soome murretes kasutatakse samadest noomenitest lähtuvaid takunimetusi vastupidises tähenduses: latvatappurat vms on 'kõige jämedamad sugetakud' ning tüve-või tüvitappurat 'peened takud'. Samamoodi kui eesti sõna märgib vepsa ladvez peenemaid takke.

\section{Kirjandus}

EEW = Julius Mägiste 1982-1983. Estnisches etymologisches Wörterbuch. I-XII. Helsinki: Finnisch-Ugrische Gesellschaft.

EKSS = Eesti keele seletav sõnaraamat. 1-6, 2009. „Eesti kirjakeele seletussõnaraamatu" 2., täiendatud ja parandatud trükk. Toim. Margit Langemets, Mai Tiits, Tiia Valdre, Leidi Veskis, Ülle Viks, Piret Voll. Eesti Keele Instituut. Tallinn: Eesti Keele Sihtasutus.

EMS $=$ Eesti murrete sõnaraamat. I-V, 1994-2011. Eesti Teaduste Akadeemia Eesti Keele Instituut. Tallinn: Eesti Keele Instituut / Eesti Keele Sihtasutus.

ERL = Gea Troska, Ants Viires, Ellen Karu, Lauri Vahtre, Igor Tõnurist 2000. Eesti rahvakultuuri leksikon. 2., täiendatud ja parandatud trükk. Koost. ja toim. Ants Viires. Tallinn: Eesti Entsüklopeediakirjastus.

Keem, Hella 1995. Tartumaa saja-aastaste jutud. Toim. Aldi Sepp. (= Valimik korrespondentide murdetekste 5.) Tallinn: Eesti Teaduste Akadeemia Emakeele Selts.

Koivulehto, Jorma 1974. Lisiä germaanis-suomalaisiin lainakosketuksiin. Virittäjä 78, 111-127.

KVVE = Kuiss vanal Võromaal eleti. 2005. Toim. Helju Kaal, Mari Must, Eevi Ross. (= Valimik korrespondentide murdetekste VI.) Eesti Teaduste Akadeemia Emakeele Selts. Tallinn: Emakeele Selts. 
Manninen, Ilmari 1933. Die Sachkultur Estlands. II. (= Õpetatud Eesti Seltsi eritoimetused II.) Tartu: Õpetatud Eesti Selts.

Ränk, Arvi 1995. Eesti etnograafiasõnaraamat. Tallinn: Õie Ränk.

Saareste, Albert 1924. Leksikaalseist vahekordadest eesti murretes. I. Analüüs 60 kaardi ja 1 skeemiga. Résumé: Du sectionnement lexicologique dans les patois estoniens. I. Analyse avec 60 cartes et 1 esquisse schématique (= Acta et Commentationes Universitatis Dorpatensis. B VI, 1.) Tartu.

SKES $=$ Erkki Itkonen, Yrjö H. Toivonen, Aulis J. Joki 1955-1981. Suomen kielen etymologinen sanakirja. (= Lexica Societatis Fenno-Ugricae XII.) Helsinki: Suomalais-Ugrilainen Seura.

SMS $=$ Suomen murteiden sanakirja. 4, 1994; 6, 1999. (= Kotimaisten kielten tutkimuskeskuksen julkaisuja 36.) Helsinki: Kotimaisten kielten tutkimuskeskus, Painatuskeskus/Edita.

SSA = Suomen sanojen alkuperä: Etymologinen sanakirja. 1-3, 1992-2000. Päätoim. Erkki Itkonen, Ulla-Maija Kulonen. (= Suomalaisen Kirjallisuuden Seuran toimituksia 556, Kotimaisten kielten tutkimuskeskuksen julkaisuja 62.) Helsinki: Suomalaisen Kirjallisuuden Seura, Kotimaisten kielten tutkimuskeskus.

Tanning, Salme 1961. Mulgi murdetekstid. Toim. Aili Univere. (= Eesti murded 1.) Eesti NSV Teaduste Akadeemia Keele ja Kirjanduse Instituut. Tallinn: Eesti Riiklik Kirjastus.

Vaba, Lembit 1997. Uurimusi läti-eesti keelesuhetest. Tallinn/Tampere: Eesti Keele Sihtasutus, Tampereen Yliopisto.

Vasmer = Макс Фасмер 1986-1987. Этимологический словарь русского языка: в четырех томах. Изд. 2-е, стер. Перевод с немецкого и дополнения О. Н. Трубачева. Под редакцией и с предисловием проф. Б. А. Ларина. Москва: Прогресс.

Wiedemann, Ferdinand Johann 1973. Eesti-saksa sõnaraamat. EstnischDeutsches Wörterbuch. Neljas, muutmata trükk teisest, Jakob Hurda redigeeritud väljaandest. Tallinn: Valgus.

ÕS 1999 = Eesti keele sõnaraamat ÕS 1999. Toim. Tiiu Erelt. Koost. Tiina Leemets, Sirje Mäearu, Maire Raadik, Tiiu Erelt. Eesti Keele Instituut. Tallinn: Eesti Keele Sihtasutus.

ÕS 2006 = Eesti õigekeelsussõnaraamat ÕS 2006. Toim. Tiiu Erelt. Koost. Tiiu Erelt, Tiina Leemets, Sirje Mäearu, Maire Raadik. Eesti Keele Instituut. Tallinn: Eesti Keele Sihtasutus.

\section{Sõnavarakogud}

EMSUKA = Eesti murrete ja soome-ugri keelte arhiiv

SMSA $=$ Soome murrete sõnaarhiiv 


\title{
Estonian words for 'tow'
}

\author{
Vilja Oja
}

In standard Estonian and in North Estonian dialects the coarse and broken part of fibre plants (flax, hemp) separated from the finer part is called takud, the SouthEstonian counterpart being paklad. In addition, there are special terms for tow of different qualities. The coarse tow produced by scutching braked flax is called ropsitakud or ropstakud (< rops 'swingling') in standard Estonian and in most North-Estonian dialects, roogetakud (< rookima dial. 'to swingle') in the Western dialect, and in some parts of the North Estonian Central dialect area eisted or eietakud are used. The South Estonian terms are rabakpakla, rapikõ, raviku etc. ( $<$ rabama 'to swingle, to scutch') and rehikpakla or rehike in south-eastern Estonia. In some cases scutched tow is referred to with a lemm-stem noun, e.g. lemmike.

The scutched fibre was hackled two or three times, thus producing sugetakud 'hackled tow'. Starting with wide teeth, coarse tow - Est. otstakud were separated, while the following application of fine teeth produced fine tow - Est. peentakud. Most of the dialectal names of the first fraction, such as otsatakud, otsiku etc., originate in the noun ots 'end'. Fine tow has been called peentakud or peeneharjatakud in northern Estonia, plus a few single reports of ihutakud, ihuroogetakud and lagijad or lagijatakud. The South-Estonian dialect and some neighbouring subdialects use the terms laaspakla or laasikpakla, laasiku etc., while suikatsõ (pakla) are used in the Võru dialect and ladviku or ladvaotsigu in the Karksi subdialect. In the case of triple hackling the separation of fine tow was preceded by an intermediate phase producing a middle fraction called kesktakud ( $<$ kesk(mine) 'middle') or vahetakud (<vahe(pealne) 'intermediate').

Only a few terms are shared with other Finnic languages. The North-Estonian general term takk 'tow' occurs in the Ingrian and Votic languages and in some Finnish dialects. The South-Estonian general term pakal is a Latvian loan while its Votic counterpart pakli comes from Russian. Closest to Finnish are the Estonian terms for the middle fraction.

Keywords: takk 'tow', pakal 'tow', ropsitakud 'scutched tow', sugetakud 'hackled tow', areal maps of tow names, Estonian dialects

Vilja Oja

keeleajaloo ja -teaduse osakond

Eesti Keele Instituut

Roosikrantsi 6

10119 Tallinn

Vilja.Oja@eki.ee 